\title{
Heat Losses from Babies in Incubators
}

\author{
E. N. HEY and L. E. MOUNT \\ From the Medical Research Council Research Group on Respiration and Energy Metabolism in the Newborn, \\ London Hospital Medical College, London E.1, and A.R.C. Institute of Animal Physiology, Babraham, \\ Cambridge
}

Incubators are now widely employed for nursing premature and ill newborn infants, because they provide a shielded and warm environment in which temperature, relative humidity, and oxygen content can be conveniently controlled. Infants are frequently nursed naked, which makes accurate observation of them easier and diminishes the amount of handling necessary. In these circumstances it is clearly important to be able to assess the adequacy of the warmth provided by the incubator.

Two types of incubator have been investigated, one depending on natural convection for the internal distribution of warmed air, and the other depending on forced convection. Natural convection is the term applied to the movement of air produced by heat; the upward current of air over a hot stove is a familiar example. Forced convection takes place when an external force, such as a fan, produces an air current. Natural convection depends on localized density changes in the air; forced convection depends on outside means being used to control air movement. The main results are presented and discussed below, but, for convenience, details of the methods employed and certain technical arguments have been relegated to an Appendix. A brief preliminary account of this work has already been published (Hey and Mount, 1966).

Heat exchange occurs through four main channels: conduction, convection, radiation, and evaporation. The measurement of air temperature within an incubator provides some indication of the likely heat loss by convection, but no indication of the losses by the other channels, and to determine the nature of the thermal environment provided by an incubator it is necessary to assess the heat exchange from each of these four channels separately. When this is done it becomes clear that the radiant heat loss suffered by the infant can be substantial.

In order to keep the infant warm, the incubator air is heated and its temperature monitored with a thermometer. The incubator walls, however, are

Received June 27, 1966. colder than the air; the mean temperature of the walls may be almost midway between that of the room and that of the air within the incubator. If there is little air movement, radiant heat loss from the skin to the cold walls of the incubator is at least as important as convective heat loss, and may lead to a large heat loss from a naked baby. Continuous heat loss due to this cause could be serious, particularly for a tiny premature infant ill with respiratory distress or cardiac failure.

It can, however, be shown that such losses are reduced and controlled by the interposition of suitable thin baffles (opaque to long wave blackbody radiation) in a warm air-stream inside the incubator between the infant and some or all of the incubator walls. The surface of such a baffle quickly reaches equilibrium at much the same temperature as the warm incubator air on either side, and effectively shields the infant from the cold outer wall, dome, or lid. A simple, cheap, and efficient shield working on this principle can be conveniently made of $1 \mathrm{~mm}$. thick transparent Perspex, and can be so mounted that it neither interferes with nursing care, nor increases the complexity of the equipment.

\section{Assessment of a Natural Convection Incubator}

For the present study an Oxygenaire Series III incubator was chosen as this is one of the most widely used incubators in this country. This welltried model works on the principle of natural convection (Fig. 1).

A low wattage heater below a metal water tank heats both the surrounding air and the tank. The warmed air heats the baffle plate and mattress tray and rises round its edges to warm the Perspex walls of the incubator before cooling or escaping from the outlet holes at the top. The mattress is warmed mainly by contact with the tray, and itself sets up secondary warm air convection currents in the main nursing compartment of the incubator. 


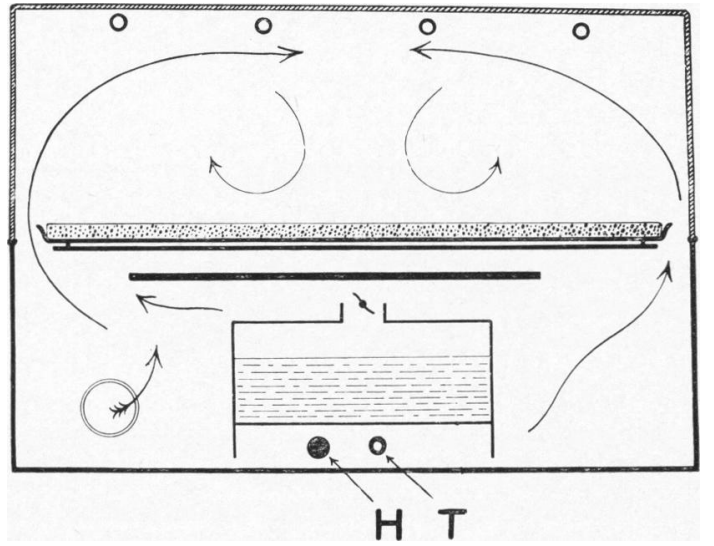

FIG. 1.-A natural convection incubator. Heater: $H$; Thermostat: $T$.

Conductive heat exchange. An exchange of heat may be expected to occur through the mattress between the baby and the tray underneath. The magnitude of this exchange will depend on the baby's skin temperature, the area of contact, the conductive properties of the mattress, and the temperature of the tray. Measurements showed that the insulating properties of the $1 \mathrm{~cm}$.-thick plastic foam mattress were very high. (The conductance of a $1 \mathrm{~cm}$.-thick layer was estimated to be $2 \mathrm{kcal} . / \mathrm{m} .{ }^{2} \mathrm{hr}$. ${ }^{\circ} \mathrm{C}$., or similar to that of cotton wool or still air.) Since in normal use the temperature of the baby's skin in contact with the mattress approximates to deep body temperature, while the temperature of the tray under the mattress is less than $3^{\circ} \mathrm{C}$. above this, the conductive heat gain is almost negligible.

Convective heat exchange. The convective heat loss from the baby's exposed surface area

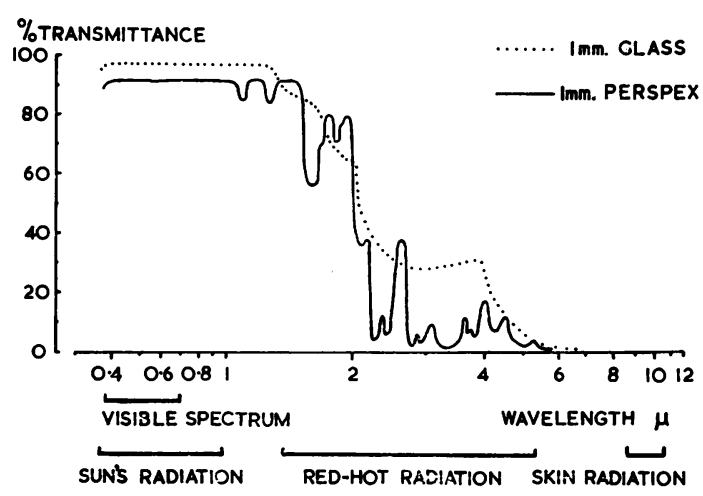

FIG. 2.-Transmission properties of $1 \mathrm{~mm}$. glass and $1 \mathrm{~mm}$. Perspex. depends on both the difference between skin and air temperatures and on the speed of air movement. Radiant and convective heat loss are usually measured together, and the convective component is estimated by subtracting the calculated radiant loss. A knowledge of air speed and mean air temperature is, however, necessary if different environments are to be compared in respect of convective loss.

Air movement was measured at various points above the mattress and shown to be very low $(3-8 \mathrm{~cm} . / \mathrm{sec}$.), being greatest in the main convective air currents. Marked air temperature gradients must of necessity exist in any incubator that works on the principle of natural warm air convection; the nature and extent of these gradients were determined by taking multiple temperature measurements with thermocouples within the incubator. The temperature of the mattress itself and of the air immediately above it was fairly even, and this agreed with the temperature recorded by the incubator thermometer. Marked layering of warmer air occurred in the upper half of the incubator, however, with variable gradients of $3-4^{\circ} \mathrm{C}$. or more, and convection currents of even warmer air could be found rising up part of the side walls immediately above the tank and baffle.

Radiant heat exchange. Heat exchange occurs between bodies at different temperatures by direct radiation, independently of heat transfer by convection, in the same way as a light beam crosses a vacuum. Perspex, like glass, transmits radiation at wavelengths around those of the visible spectrum. Both substances are, however, opaque to radiant heat from surfaces at low temperatures (such as the walls of a room or human skin) which have wavelengths of maximum emission of 9-10 $\mu$. Such radiant heat, when it is not reflected, is absorbed by the glass or Perspex, which warm up as a result (Fig. 2).

It is this property of glass that underlies the greenhouse principle, and in this respect a Perspex incubator and a glass greenhouse are strikingly similar (Fig. 3). The Perspex absorbs the long wave radiation from the walls and surroundings and from within the incubator until a radiant and convective equilibrium is established, but radiation from the sun passes through the Perspex into the incubator to be absorbed by the infant and the mattress. Since long wave re-radiation through the warm Perspex is prevented, dangerous hyperthermia would clearly be possible.

In normal clinical use incubators are seldom subjected to direct sunlight or other important sources of short wavelength radiant heat, and the 
baby exchanges radiant heat only with the mattress and the inner surface of the incubator. The magnitude of this exchange can be assessed once the infant's effective radiating surface area, its mean skin temperature, and the mean surface temperature of the mattress and of the inside of the Perspex walls are known.

An Oxygenaire Series III incubator was, therefore, placed in a temperature-controlled room and measurements of the temperature of the mattress and of the inner and outer surfaces of the Perspex were obtained with thermocouples held in place with adhesive tape. Incubator air temperature (defined in accordance with British Standards Institute practice as the mean air temperature $5 \mathrm{~cm}$. above the mattress) was kept constant at $32^{\circ} \mathrm{C}$. $\left(90^{\circ} \mathrm{F}\right.$.) and a series of readings was obtained at six different room temperatures between 14 and $26^{\circ} \mathrm{C}$. $\left(57-79^{\circ}\right.$ F.). Marked regional variations in Perspex temperature were found, due to the presence of localized warm air convection currents close to the inner wall; mean temperatures were therefore calculated from a hundred or more inner surface thermocouple readings at each of the six room temperatures. Mattress temperatures were found to be very similar to the reference air temperature recorded $5 \mathrm{~cm}$. above the centre, but the mean Perspex wall temperature was found to be almost halfway down the gradient between room temperature and incubator air temperature, as defined above. There was a thin boundary layer of still air on either side, and it was in these boundary layers that most of the temperature gradient occurred (Fig. 4).

It is well known that in such circumstances thermocouples fail to measure surface temperature accurately. The radiating temperature of each surface was therefore also measured with a radiometer. This demonstrated that when there was a $7^{\circ} \mathrm{C}$. difference between surface and air temperature the thermocouples were in error by nearly $1^{\circ} \mathrm{C}$.

Estimates of the mean radiating temperature of the surrounding structures were also obtained with a slightly smaller version of the globe thermometer introduced by Bedford and Warner (1934), at a point $10 \mathrm{~cm}$. above the centre of the mattress. The estimates obtained (Table) agreed satisfactorily with those predicted on the basis of the surface temperature information available in Fig. 5 (see Appendix). It is clear that when the room is $15^{\circ} \mathrm{C}$. colder than the air in the incubator, the infant will suffer a considerable radiant heat loss to the Perspex wall, since this is some $6^{\circ} \mathrm{C}$. colder than the air round the baby. The colder the room the greater this loss, even though the incubator air temperature remains constant.

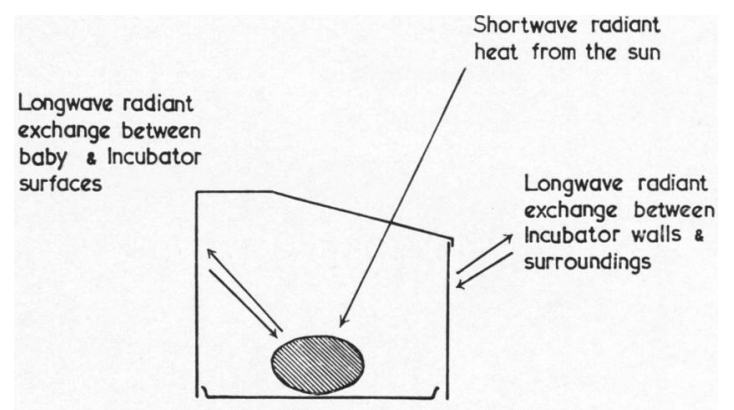

FIG. 3.-The 'greenhouse' effect.

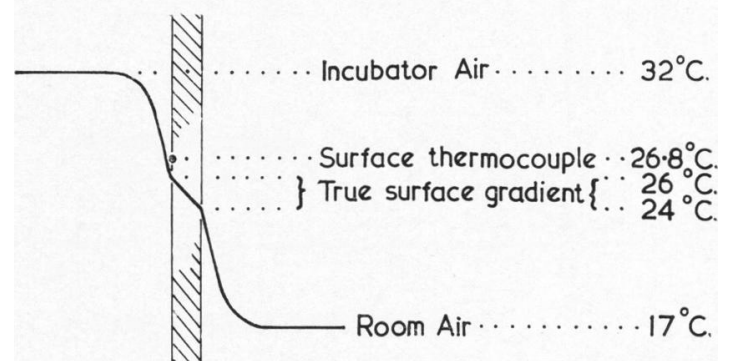

INCUBATOR NO ROOM

FIg. 4.-Temperature gradients across a $9 \mathrm{~mm}$. Perspex incubator wall (width of the boundary layers not drawn to scale).

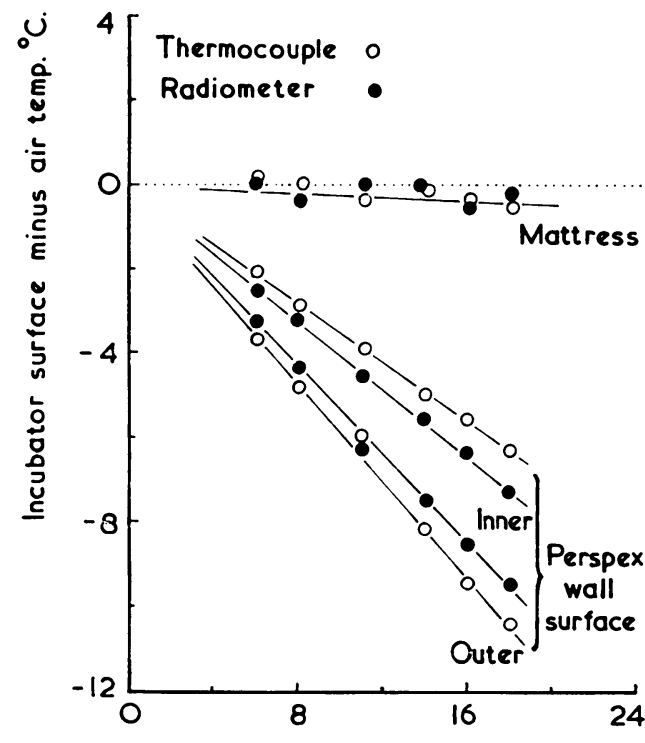

Incubator minus room air temp. ${ }^{\circ} \mathrm{C}$

FIG. 5.-Thermocouple and radiometer estimates of the relation between incubator air and mean surface temperatures in a natural convection incubator. 


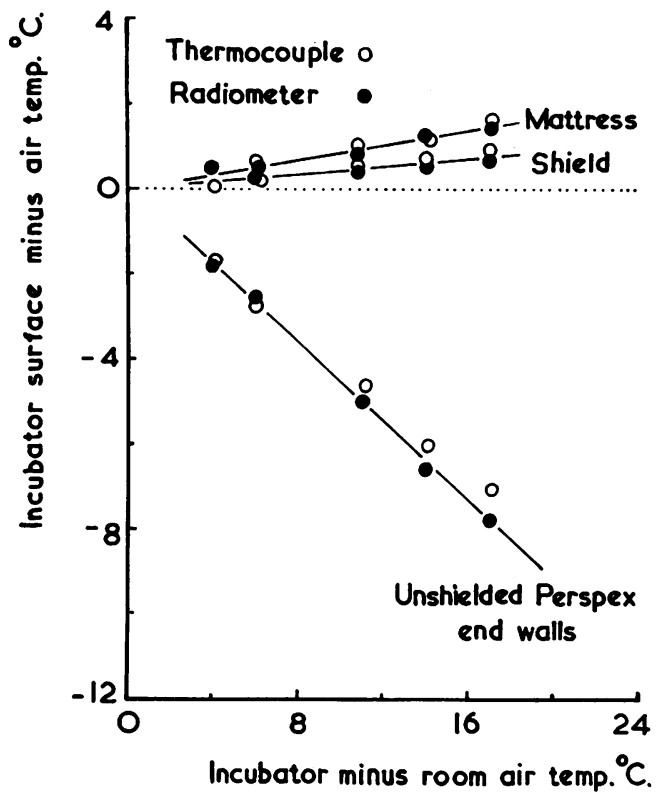

FIG. 6.-Thermocouple and radiometer estimates of the relation between incubator air and mean inner surface temperatures with a radiant shield in place in a natural convection incubator.

Radiant shield. A simple three-sided selfsupporting inverted shield of clear $1 \mathrm{~mm}$. Perspex, $50 \mathrm{~cm}$. long, $25 \mathrm{~cm}$. wide, and $18 \mathrm{~cm}$. high was then

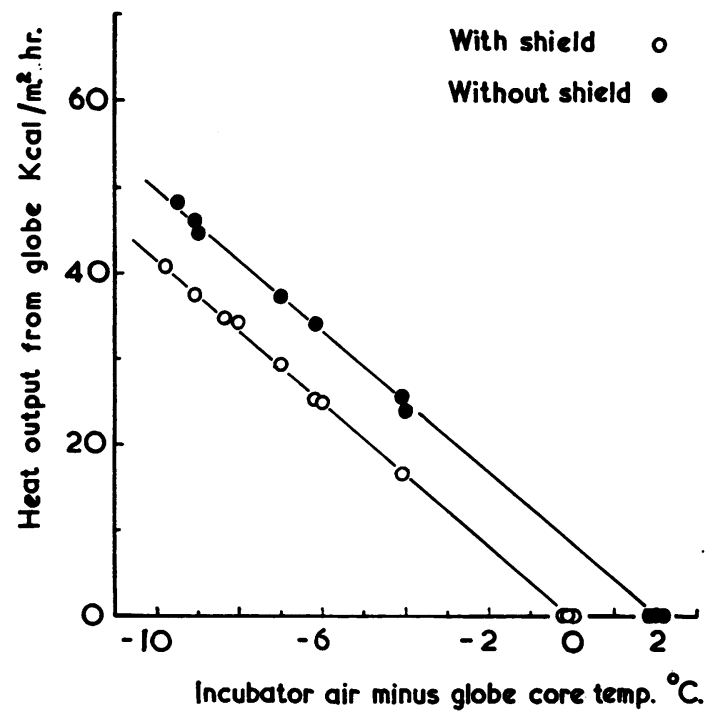

FIG. 7.-Heat loss from an electrically heated $11 \mathrm{~cm}$. globe placed centrally within an incubator with and without the radiant shield in place. Incubator air $32^{\circ} \mathrm{C}$.; room $16^{\circ} \mathrm{C}$.
TABLE

Globe Thermometer Estimates of Mean Radiant Temperature in ${ }^{\circ} \mathrm{C}$. at a Point $10 \mathrm{~cm}$. Above the Centre of the Series III Incubator Mattress at a Constant Incubator Air Temperature and a Range of Room Temperatures

\begin{tabular}{c|c|c}
\hline $\begin{array}{c}\text { Room } \\
\text { Temperature } \\
\left({ }^{\circ} \mathrm{C} .\right)\end{array}$ & Incubator Temperatures $\left({ }^{\circ} \mathrm{C}.\right)$ \\
\cline { 2 - 3 } $26 \cdot 0$ & Air & Radiant \\
\hline 24.0 & $32 \cdot 0$ & $30 \cdot 6$ \\
$20 \cdot 9$ & 31.9 & $30 \cdot 0$ \\
$18 \cdot 1$ & 32.0 & $29 \cdot 5$ \\
15.9 & $32 \cdot 1$ & $28 \cdot 7$ \\
14.0 & 31.9 & $28 \cdot 2$ \\
& 32.0 & $27 \cdot 8$ \\
\hline
\end{tabular}

placed inside the incubator centrally over the mattress. Since there was warm air on both sides of it, the shield quickly reached almost the same temperature as the surrounding air. Estimates of the mean radiating temperature of the mattress, the shield, and the unshielded end walls were then obtained at various room temperatures and plotted in the same manner as before (Fig. 6). Since the shield was so much warmer than the main incubator walls, the radiant heat loss of any object inside was substantially reduced and the surface temperature of the mattress rose. Estimates from radiometer readings agreed with those obtained using the $11 \mathrm{~cm}$. globe, and indicated that the mean radiating temperature of the surroundings was now almost identical with that of the air in the incubator.

A small electric heating coil was then placed inside the globe, and the wattage required to raise the temperature at the centre $4-9^{\circ} \mathrm{C}$. above that of the surrounding air was measured with and without the radiant shield in place (Fig. 7). The extra wattage necessary to maintain the central globe temperature when the shield was removed was proportional to the difference between incubator air temperature and room temperature.

Humidity. The tests outlined above were undertaken with low incubator humidity $(20-30 \% \mathrm{RH})$. They were then repeated at the highest humidity obtainable $(70-80 \% \mathrm{RH})$ when the room was $16^{\circ} \mathrm{C}$. colder than the incubator reference point air temperature, and the room humidity was $50-55 \%$. Increasing the humidity by opening the butterfly valve at the top of the water tank increased both air and wall temperatures almost equally and by up to $1 \frac{1}{2}^{\circ} \mathrm{C}$. at any given thermostat setting, but did not otherwise alter the relationships summarized in Fig. 5, 6, and 7. 


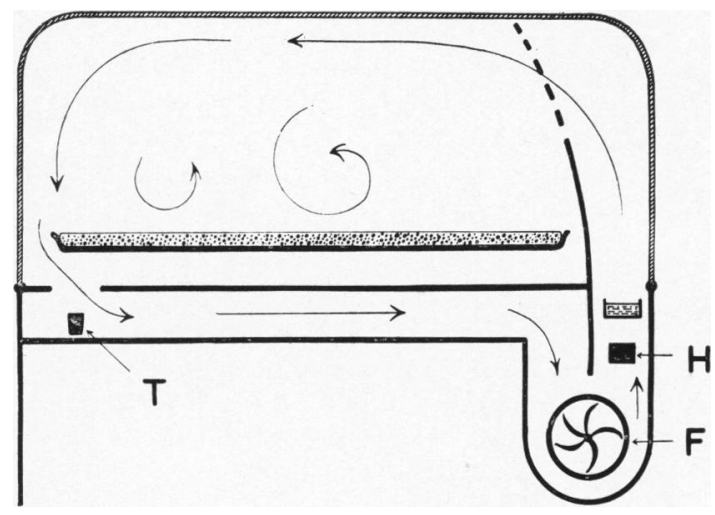

FIG. 8.-A forced convection incubator. Fan: $F$; heater: $H$; thermistor: $T$.

\section{Assessment of a Forced Convection Incubator}

The investigations described above were then repeated on a recently developed Oxygenaire incubator in which air is circulated through the incubator with a small fan, and warm air on entry is first deflected by a baffle towards the dome of the incubator (Fig. 8). The air is warmed by a continuously proportional heater controlled by thermistors at the air outlet from the main chamber. Air movement was checked and found to be low $(4-10 \mathrm{~cm} . / \mathrm{sec}$.) above the mattress but higher $(10-30 \mathrm{~cm} . / \mathrm{sec}$.) near the dome. The mattress was cooler than in the Series III incubator because it was warmed only by the circulating air in the main incubator chamber, and when a baby was placed in it there was a small but detectable conductive heat loss from the baby through the mattress. The inner Perspex wall surface was warmer, but the combined weighted mean radiant temperature from both mattress and walls assessed at a point $10 \mathrm{~cm}$. above the mattress was very similar to that in the Series III incubator. When a shaped thin inner shield of transparent Perspex was placed inside the incubator, it soon warmed up to almost the same temperature as the incubator air, and the surface temperature of the mattress rose somewhat (Fig. 9). These findings were confirmed with the heated sphere.

\section{Clinical Tests and Measurements}

Additional clinical tests were undertaken with the Series III incubator. Heat flow discs were placed under four healthy newborn full-term infants while they lay on the mattress. These confirmed that the infant gained heat by conduction at the rate of about $4 \mathrm{kcal}$. per hour per square metre of surface contact.

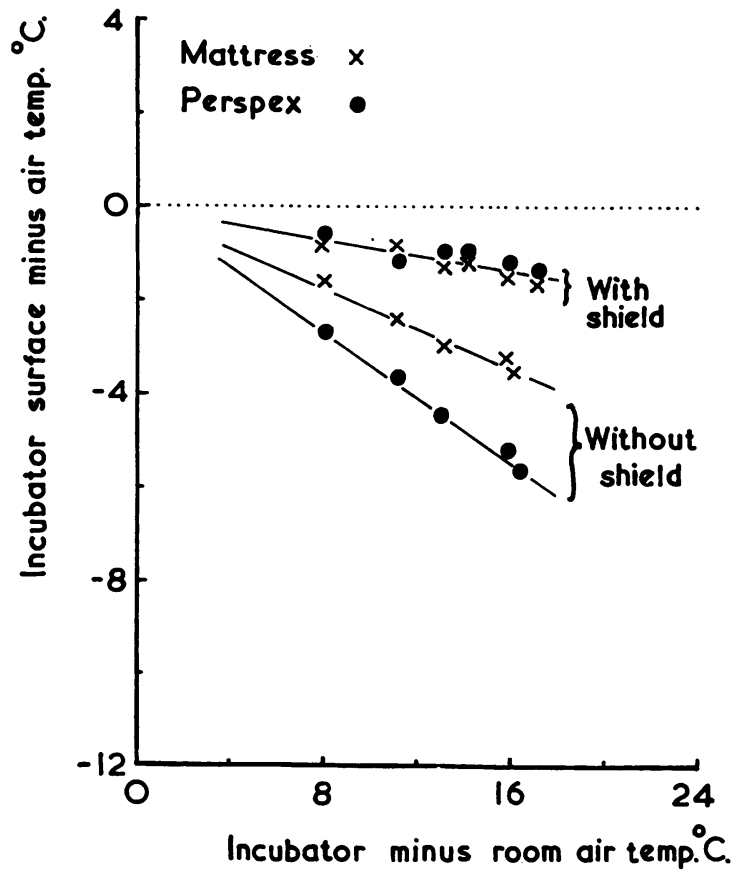

Fig. 9.-The relation between incubator air and mean inner surface temperatures with and without a radiant shield in place in a forced convection incubator. (Only the radiometer estimates of surface temperature have been plotted.)

This amounts to a total of about $0 \cdot 2 \mathrm{kcal} . / \mathrm{hr}$., or not more than $4 \%$ of the baby's heat exchange.

Further tests were undertaken to show the efficiency of the radiant shield. Environmental, skin, and rectal temperatures were measured with thermocouples, and recorded until stable, with and without the shield in place. Measurements of regional heat loss were also made in infants by placing heat flow discs on the abdomen. The presence of the shield had a significant effect on mean skin temperature (Fig. 10). The change in the skin temperature of the infant's extremities was often marked, and the increase in skin temperature when the shield was in place was clearly correlated with a decrease in heat loss recorded by the heat flow disc (Fig. 11).

Measurements of oxygen consumption were also made while the infant was in the incubator with and without the shield. Six satisfactory paired estimates of oxygen consumption were obtained with the infant quiet and motionless (Fig. 12). Oxygen consumption was significantly lower in the presence of the shield (a paired-variate t-test gave $p=0.02$ ) independent of the order in which the measurements were made. 


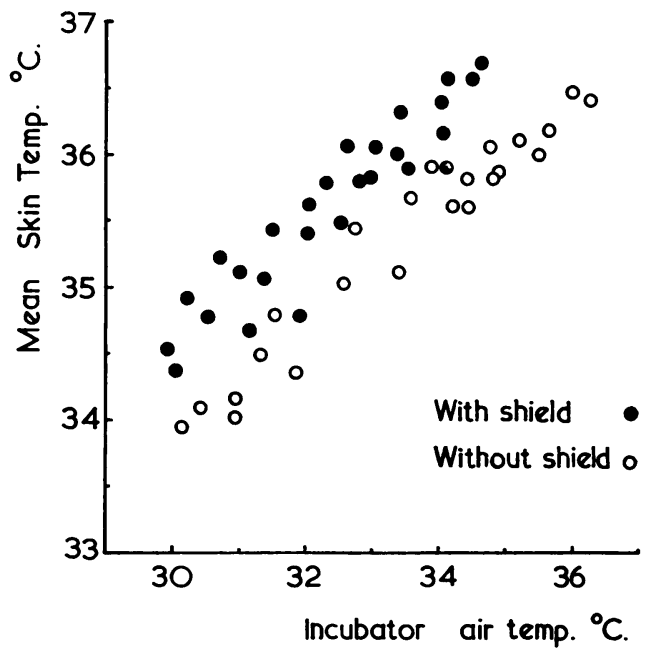

FIG. 10.-The effect of the radiant shield on the mean skin temperatures of a series of 13 healthy full-term naked babies. Room temperature $20-22^{\circ} \mathrm{C}$.

\section{Discussion}

Research work in the past ten years has confirmed and enlarged on the pioneering studies of Day, Curtis, and Kelly (1943) on how a naked baby maintains its body temperature at various environ-

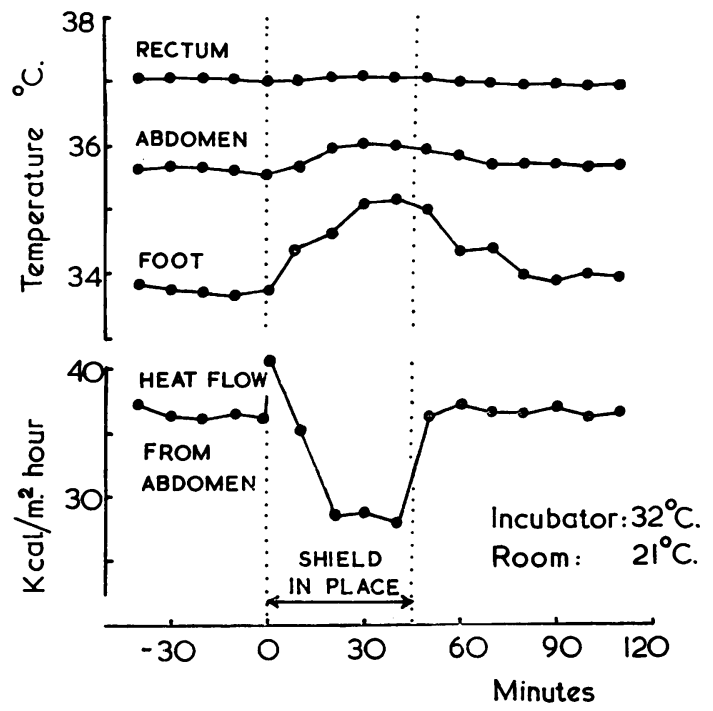

FIG. 11.-The effect of the radiant shield on an infant's heat loss and skin temperatures at a constant incubator air temperature. (Note the transient increase in heat flow from the abdomen when the cold shield at $21^{\circ} \mathrm{C}$. is first placed in the incubator.)

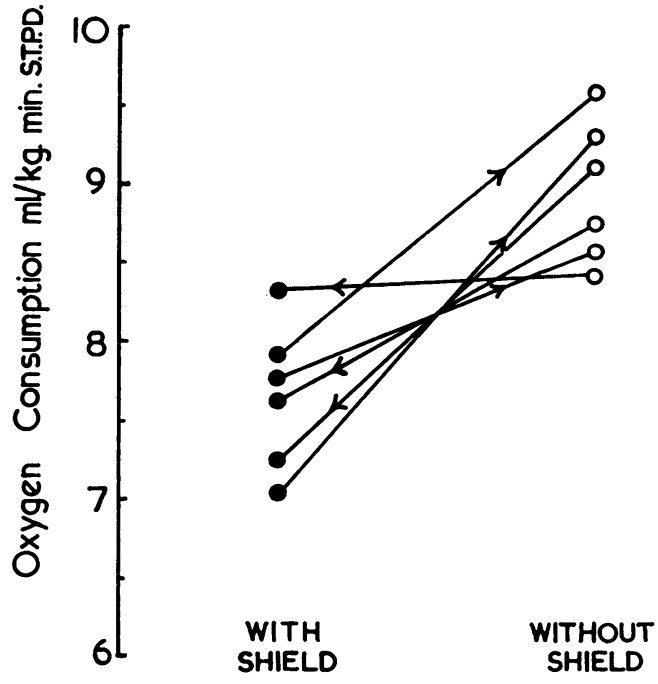

FIG. 12.-The resting oxygen consumption of six healthy newborn infants in an incubator with and without the radiant shield in place. Incubator air $32^{\circ} \mathrm{C} . ;$ room 20-22 ${ }^{\circ}$.

mental temperatures. The majority of investigations have been undertaken under conditions of low air movement and moderate humidity (40-60\% $\mathrm{RH}$ ), with the temperature of the air and the surrounding walls nearly identical. Under these

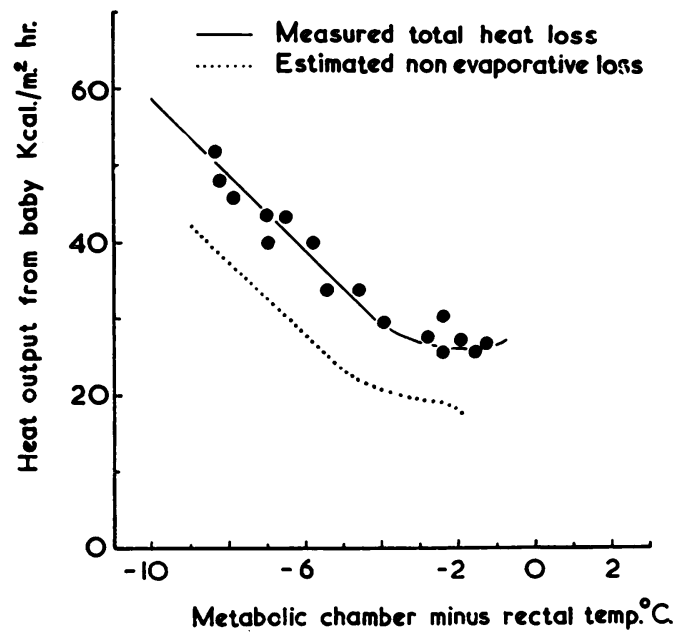

FIG. 13.-The relation between rectal temperature, metabolic chamber temperature, and heat output for a typical newborn premature baby assuming heat output in kcal. $=4.8 \times$ oxygen consumption in litres STPD \pm heat storage (E. N. Hey, unpublished data.) 
conditions a naked newborn premature infant can maintain its body temperature by changes in skin blood flow when the environmental temperature is not more than $2-3^{\circ} \mathrm{C}$. below its rectal temperature (and it is said to be in a neutral thermal environment). If the gradient between rectal and environmental temperatures exceeds $2-3^{\circ} \mathrm{C}$., the infant has to generate extra heat above the minimal basal levels in order to maintain body temperature (Brück, 1961; Hill and Rahimtulla, 1965; Scopes, 1966), and this is reflected in increased oxygen consumption (Fig. 13).

Measurements have indicated that conductive heat exchange in the incubators investigated accounts for only about $1 \mathrm{kcal} . / \mathrm{m} .{ }^{2} \mathrm{hr}$. of the total heat exchange. There is evidence to suggest that at rest and under conditions of moderate humidity between 7 and $9 \mathrm{kcal} . / \mathrm{m} .^{2} \mathrm{hr}$. of the infant's heat loss occurs by evaporation (Levine, Kelly, and Wilson, 1930; Day et al., 1943) and the remainder by radiation and convection. Recent work (Mestyán, Járai, Bata, and Fekete, 1964a, b; Levison and Swyer, 1964; Adamsons, Gandy, and James, 1965) has shown that the newborn infant is very responsive to changes in radiant temperature, and that radiant heat loss is probably at least as important as convective loss. The measurements of skin heat flow and skin temperature reported above support this conclusion. Accurate estimates of the radiant: convective partition have not yet been made on the newborn infant, but in the adult Burton and Edholm (1955) calculated on the data established by Winslow, Gagge, and Herrington (1939) that under conditions of low air movement radiation accounts for $55 \%$ of the nonevaporative heat loss, while Hardy and Du Bois (1938) found the proportion to be even higher, and Mount (1964) has shown that under these conditions radiant heat exchange is at least as large as convective heat exchange in the newborn pig weighing $1-2 \mathrm{~kg}$. at birth.

It is therefore probable that non-evaporative heat loss from the newborn baby will behave in a similar way to heat loss from the heated $11 \mathrm{~cm}$. globe (compare Fig. 7 and Fig. 13) and that heat loss will be correspondingly increased when the incubator walls are colder than the air inside. On this basis it may be predicted (see Appendix) that a small newborn premature infant placed in such an incubator with an air temperature of $34^{\circ} \mathrm{C}$. $\left(93^{\circ} \mathrm{F}\right.$.) in a room at $20^{\circ} \mathrm{C}$. $\left(68^{\circ} \mathrm{F}\right.$.) will have to increase its oxygen consumption by nearly $25 \%$ above the basal level in order to maintain its body temperature at $37^{\circ} \mathrm{C}$. if the radiant heat loss to the cold walls of the incubator is not reduced. Silverman and Agate (1964) have indeed shown that many small premature infants are not in the thermoneutral range when nursed in standard incubators with an air temperature of $34^{\circ} \mathrm{C}$., and that in consequence either their oxygen consumption increases significantly or their body temperature falls. Such an increased demand could have serious consequences for an infant in respiratory distress or cardiac failure. A number of investigations in recent years (Silverman, Fertig, and Berger, 1958; Jolly, Molyneux, and Newell, 1962; Day, Caliguiri, Kamenski, and Ehrlich, 1964; Buetow and Klein, 1964) has shown in controlled clinical trials that even small increases in operative incubator temperature can significantly decrease infant mortality.

It has long been realized that room temperature can affect incubator air temperature even in thermostatically controlled incubators. Gleiss (1957) suggested that double glazing might solve this problem by decreasing conductive heat losses through the Perspex. From the foregoing analysis it seems that the main problem is to cut down the infant's radiant heat loss, and in these circumstances a thin inner Perspex shield, so positioned that there is a free circulation of the incubator's warm air on both sides, will be more effective than sealed doubleglazing. This represents a simple and effective method of producing in the incubator a thermal environment that is largely independent of fluctuations in room temperature, while at the same time the shield can be so shaped and mounted that it neither interferes with nursing care nor increases the complexity of the equipment.

Clothing the infant will reduce both convective and radiant heat loss but only at the expense of most of the remaining advantages which an incubator possesses over a Charlotte's box or heated cot. More complicated solutions of the problem, using a radiant heat source controlled by a temperature sensor strapped to the infant's skin, have been developed in America (Agate and Silverman, 1963; Rodaway and Oliver, 1965). No detailed analyses of the infant's mean radiant and convective environment under these conditions have yet been published, however. If it is not possible to reduce radiant loss by placing the incubator in a room that is warm enough, it is of course possible to compensate by increasing incubator air temperature, but it is doubtful if this is the ideal solution. By placing the sensing probe controlling air temperature inside a small black globe it would be possible to make the incubator compensate automatically in this way for changes in mean radiant as well as air temperature, but it is difficult to find a suitable position for the globe. In any case modern safety standards (British Standards Institution, 1965) stipulate that incubators should be so constructed that the air 
temperature $5 \mathrm{~cm}$. above the mattress does not exceed $35^{\circ}$ C. $\left(95^{\circ}\right.$ F.).

\section{Summary}

Simple methods by which the thermal environment provided by an incubator can be measured and analysed into conductive, convective, radiant, and evaporative components have been developed and applied to two commercial incubators working on different principles. Radiant heat losses were found to be considerable unless room temperature was unusually high. It is predicted that a naked newborn premature infant placed in such an incubator with the air at $34^{\circ} \mathrm{C}$. $\left(93^{\circ} \mathrm{F}\right.$.) will need to increase its oxygen consumption $25 \%$ above the basal level to maintain its body temperature at $37^{\circ} \mathrm{C}$. if the room temperature is $20^{\circ} \mathrm{C}$. $\left(68^{\circ} \mathrm{F}\right.$.). The clinical significance of these findings is discussed and various methods of reducing or compensating for these losses are suggested.

We are greatly indebted to Oxygenaire Ltd. for their co-operation, for the loan of equipment, and for a grant towards the costs incurred.

We also wish to thank Mrs. Susan Hey, S.R.N., Mr. A. J. Legge, and Mr. I. B. Start for their help with the numerous measurements and tests, and Dr. M. H. Hey for help with the calculation of solid angles.

\section{REFERENCES}

Adamsons, K., Gandy, G. M., and James, L. S. (1965). The influence of thermal factors upon oxygen consumption of the newborn human infant. F. Pediat., 66, 495.

Agate, F. J., and Silverman, W. A. (1963). The control of body temperature in the small newborn infant by low-energy infrared radiation. Pediatrics, 31, 725 .

Bedford, T., and Warner, C. G. (1934). The globe thermometer in studies of heating and ventilation. f. Hyg. (Lond.), 34, 458.

British Standards Institution (1965). Specification for electricallyheated incubators for babies. B.S. 3061 : 1965. British Standards Institution, London.

Brück, K. (1961). Temperature regulation in the newborn infant. Biol. Neonat. (Basel), 3, 65.

Buetow, K. C., and Klein, S. W. (1964). Effect of maintenance of 'normal' skin temperature on survival of infants of low birth weight. Pediatrics, 34, 163.

Burton, A. C., and Edholm, O. G. (1955). Man in a Cold Environment, pp. 49-51. Arnold, London.

Day, R., Curtis, J., and Kelly, M. (1943). Respiratory metabolism in infancy and in childhood. Amer. F. Dis. Child., 65, 376.

Day, R. L., Caliguiri, L., Kamenski, C., and Ehrlich, F. (1964). Body temperature and survival of premature infants. Pediatrics, 34, 171.

Gleiss, J. (1957). Uber die Wärmeregulation des frühgeborenen Kindes in klimatisierten Inkubatoren. Z. Kinderheilk., 79, 147.

Golinko, R. J., and Rudolph, A. M. (1961). A valve for respiratory studies in infants. Pediatrics, 27, 645.

Hardy, J. D., and Du Bois, E. F. (1938). Basal metabolism, radiation, convection and vaporization at temperatures of 22 to $35^{\circ}$ C. F. Nutr., 15, 477 .

Hatfield, H. S., and Wilkins, F. J. (1950). A new heat-flow meter. 7. sci. Instrum., 27, 1.

Hey, E. N. (1966). A small heated respiratory valve. F. Physiol. (Lond.), 186, $49 P$.

_ , and Mount, L. (1966). Temperature control in incubators. Lancet, 2, 202
Hill, J. R., and Rahimtulla, K. A. (1965). Heat balance and the metabolic rate of newborn babies in relation to environmental temperature; and the effect of age and of weight on basal metabolic rate. F. Physiol. (Lond.), 180, 239.

Jolly, H., Molyneux, P., and Newell, D. J. (1962). A controlled study of the effect of temperature on premature babies. $\mathcal{f}$. Pediat., 60, 889.

Klein, A. D., and Scammon, R. E. (1930). The regional growth in surface area of the human body in prenatal life. Proc. Soc. exp. Biol. (N.Y.), 27, 463.

Levine, S. Z., Kelly, M., and Wilson, J. R. (1930). The insensible perspiration in infancy and in childhood. II. Proposed basal standards for infants. Amer. F. Dis. Child., 39, 917.

Levison, H., and Swyer, P. R. (1964). Oxygen consumption and the thermal environment in newly born infants. Biol. Neonat. (Basel), 7, 305.

Lloyd, B. B. (1958). A development of Haldane's gas-analysis apparatus. f. Physiol. (Lond.), 143, 5P.

McLean, J. A. (1963). Measurement of cutaneous moisture vaporization from cattle by ventilated capsules. ibid., 167,417 .

Mestyán, J., Járai, I., Bata, G., and Fekete, M. (1964a). Surface temperature versus deep body temperature and the metabolic response to cold of hypothermic premature infants. Biol. Neonat. (Basel), 7, 230.

,,--- , and $-(1964 \mathrm{~b})$. The significance of facial skin temperature in the chemical heat regulation of premature infants. ibid., 7, 243.

Molnar, G. W., and Rosenbaum, J. C., Jr. (1963). Surface temperature measurement with thermocouples. In Temperature: its Measurement and Control in Science and Industry, ed. C. M. Herzfeld, Vol. 3, Part 3, Biology and Medicine, ed. J. D. Hardy, pp. 3-11. Reinhold, New York.

Mount, L. E. (1964). Radiant and convective heat loss from the new-born pig. f. Physiol. (Lond.), 173, 96.

Rodaway, K. A., and Oliver, T. K., Jr. (1965). Incubator accessory for exchange transfusion. Lancet, $1,1220$.

Scopes, J. W. (1966). Metabolic rate and temperature control in the human baby. Brit. med. Bull., 22, 88.

Silverman, W. A., and Agate, F. J., Jr. (1964). Variation in cold resistance among small newborn infants. Biol. Neonat. (Basel), 6, 113.

-, Fertig, J. W., and Berger, A. P. (1958). The influence of the thermal environment upon the survival of newly born premature infants. Pediatrics, 22, 876.

Stillwell, G. K., Hemingway, A., and Kottke, F. J. (1955). Accuracy of thermocouples as surface thermometers. f. appl. Physiol., 8, 223.

Stoll, A. M., and Hardy, J. D. (1950). Study of thermocouples as skin thermometers. ibid., 2, 531 .

Winslow, C.-E.A., Gagge, A. P., and Herrington, L. P. (1939). The influence of air movement upon heat losses from the clothed human body. Amer. F. Physiol., 127, 505.

- Herrington, L. P., and Gagge, A. P. (1937). Physiological reactions of the human body to varying environmental temperatures. ibid., 120, 1 .

\section{Appendix on Methods}

The main series of tests was undertaken with an empty incubator in a temperature-controlled room with thin metal walls externally insulated with expanded polystyrene, so that the mean radiant temperature was within $0.5^{\circ} \mathrm{C}$. of the air temperature. A fan was used to mix the room air, but the air speed in the vicinity of the incubator was kept below $12 \mathrm{~cm}$./sec. Air movement was measured with a Simmons shielded hot wire anemometer (Tinsley and Co. Ltd.), and humidity was monitored with a wet and dry thermocouple assembly of the type described by McLean (1963) with an air sampling velocity of $100 \mathrm{~cm}$. $/ \mathrm{sec}$. Heat flow was estimated with Hatfield-Turner heat flow discs (Hatfield and Wilkins, 1950). Air and surface temperatures were measured with 36 s.w.g. copper-constantan thermo- 
couples and a Pye Scalamp galvanometer or a Cambridge DE 12-channel recorder.

It is well known that thermocouples frequently fail to measure surface temperatures accurately, since their presence affects the wall's heat exchange at the point of attachment, and since, however closely they are attached, they also measure in part the temperature of the boundary layer of air on which they encroach (Stoll and Hardy, 1950; Stillwell, Hemingway, and Kottke, 1955; Molnar and Rosenbaum, 1963). Surface temperatures were therefore also measured with a radiometer (Cambridge Instrument Co. Ltd.) after it had been calibrated against the blackened surface of a thin copper tank containing stirred water at a known temperature. As a further check on the radiometer estimates, measurements of the heat flow through the Perspex walls were made with a Hatfield disc. These indicated a heat flow of about $38 \mathrm{kcal} . / \mathrm{m} .{ }^{2} \mathrm{hr}$. for the conditions indicated in Fig. 4, when the radiometer showed a difference of $2^{\circ} \mathrm{C}$. in the temperature of the two surfaces. Given that the conductivity of Perspex at $20^{\circ} \mathrm{C}$. is $4.5 \times 10^{-4} \mathrm{cal} . / \mathrm{cm} .^{2}$ sec. ${ }^{\circ} \mathrm{C}$. per $\mathrm{cm}$., it is possible to predict that the true gradient should be $2 \cdot 1^{\circ} \mathrm{C}$. between the two surfaces.

The clinical tests were undertaken in a normal hospital room after the mothers' consent and co-operation had first been obtained. Skin temperatures were measured at 6 sites with 40 s.w.g. thermocouples held in place with small pieces of adhesive tape on either side of the junction, and were recorded every minute until stable. Averages were then calculated with weighting factors derived from Klein and Scammon's (1930) measurements of surface area. Oxygen consumption was measured by collecting duplicate timed samples of about 3 litres of expired air in a small anaesthetic gas bag. The volume of each sample was measured with a spirometer, and its $\mathrm{CO}_{2}$ and $\mathrm{O}_{2}$ content analysed, using Lloyd's (1958) modification of the Haldane gas analysis apparatus. A nasal valve of the type described by Golinko and Rudolf (1961) was first used to obtain samples, but serious difficulty was experienced in preventing condensation which upset the movement of the small ball valves. A modified valve was, therefore, constructed with a small warm outer jacket to prevent condensation near the valve (Hey, 1966), and this proved more reliable.

Estimates of the over-all mean radiant temperature were obtained using a globe thermometer. The surface of the globe equilibrates with the surrounding mean radiant and air temperatures, and the resulting equilibrium is reflected by the air temperature at the centre of the globe. Bedford and Warner (1934) used a thin blackened copper globe $15 \mathrm{~cm}$. in diameter. Such a globe is rather too big for use conveniently inside an incubator where air temperature is only reasonably constant over a restricted region immediately above the mattress. A slightly smaller globe $11 \mathrm{~cm}$. in diameter was therefore constructed and calibrated by establishing its radiant : convective partition in nearly still air conditions (air speed 3-10 cm. $/ \mathrm{sec}$.), in a manner similar to that employed by Bedford and Warner.

The globe was then employed to obtain estimates of the integrated mean environmental radiant temperature under comparable conditions of air movement inside the incubator (Table). Its centre was positioned above the middle of the mattress, and surrounding air temperatures were measured with five thermocouples placed at varying heights round and $5 \mathrm{~cm}$. from the globe. The dimensions of the mattress were $78 \times 38 \mathrm{~cm}$., with a lip at the edge nearly $2 \mathrm{~cm}$. high. It could, therefore, be estimated by spherical trigonometry that $61 \%$ of the total solid angle subtended at the centre of the globe exchanged radiant heat with the Perspex and the remainder with the mattress. As a cross-check, therefore, the mean radiant temperature at this point $\left(T_{R}\right)$ could also be calculated from the data on the mean temperatures of the Perspex wall $\left(T_{w}\right)$ and mattress $\left(T_{w}\right)$ contained in Fig. 5 and 9 from the relation:

$$
T_{R}-T_{I}=0.61\left(T_{W}-T_{I}\right)+0.39\left(T_{M}-T_{I}\right),
$$

where $T_{1}$ is the air temperature at the reference point $5 \mathrm{~cm}$. above the centre of the mattress. (Over this temperature range the temperature difference may be used instead of the difference between the fourth powers, as required by the Stefan-Boltzmann Law, with very little error (Burton and Edholm, 1955).) Similar predictions on the basis of the data in Fig. 6 were obtained on an assessment that with the radiant shield in place $63 \%$ of all radiation to the globe was from the shield, $28.5 \%$ from the mattress, and $8.5 \%$ from the unshielded end walls of the incubator. Globe estimates of radiant temperature differed from the predictions by less than $+0.3^{\circ} \mathrm{C}$.

There are, however, approximations inherent in the use of the above equation. Mean air temperature round the globe was always higher than that of the air $5 \mathrm{~cm}$. above the mattress. Correction for this increased the discrepancy between the estimates. Neither is it really appropriate to use mean surface temperature where equal areas are given equal weights in respect of temperature measurement irrespective of size of the solid angle they subtended at the globe. Revised estimates were, therefore, obtained by weighting each individual surface temperature reading inversely by the square of its distance from the globe. Since those surfaces nearest the globe tended to be warmer than the average, this increased the predicted mean radiant temperature. After applying both the above corrections, the estimates of the mean radiant temperature obtained by the globe and predicted from the known surface temperatures differed by no more than $+0.11^{\circ} \mathrm{C}$. It seems possible that failure to allow for a little reflection from the polished Perspex in the above predictions may be partially responsible for the remaining small positive discrepancies. Certainly there is nothing in these estimates to conflict with the assumption that Perspex is completely opaque to black body radiation, and that mean radiant temperature can be adequately predicted from a complete knowledge of surface temperature within the incubator.

Using similar arguments it can also be shown that, because of the baby's shape and because the various surrounding surfaces do not have identical temperatures, the mean radiant temperature experienced by the baby will not be exactly the same either as that calculated above 
or as that recorded by the globe thermometer. A computer was employed to calculate the solid angles subtended by the several surrounding surfaces at each of some 1600 points on a simple 'model baby' (a cylinder with hemispherical ends, truncated by a plane-the bed - parallel to its axis), and hence the mean radiant temperature of the surroundings as seen from the surface of the model. The estimates of mean radiant environment did not differ sufficiently from those predicted for a point $5 \mathrm{~cm}$. above the centre of the mattress to justify the use of this further refinement in the prediction of the effective radiant temperature for the conditions investigated in this paper. Such correction would, however, be essential where the baby was exposed to a localized spot source of radiant heat.

If conductive heat exchange is small enough to be ignored, and an approximate estimate of the relative importance of radiant and convective heat losses from the baby is available, it is possible to calculate an 'operative' environmental temperature (Winslow, Herrington, and Gagge, 1937). Thus, assuming a $6: 4$ radiant : convec- tive partition when incubator air temperature is $34^{\circ} \mathrm{C}$., room temperature $20^{\circ} \mathrm{C}$., and mean radiant temperature $5 \mathrm{~cm}$. above the centre of the mattress $30 \cdot 7^{\circ} \mathrm{C}$., the operative temperature is $(30.7 \times 0.6)+(34.0 \times 0.4)$ $=32 \cdot 0^{\circ} \mathrm{C}$. That is to say the true environmental temperature is $2^{\circ} \mathrm{C}$. below the temperature shown by the incubator thermometer. While such a difference may not seem large, Hill and Rahimtulla (1965) and Scopes (1966) have shown that such a decrease of $2^{\circ} \mathrm{C}$. in operative environmental temperature may necessitate a $25 \%$ increase in a naked premature infant's oxygen consumption if body temperature is not to fall (see also Fig. 13). Indirect confirmation of the validity of these estimates and the assumption made about the baby's radiant : convective partition is provided by the results summarized in Fig. 10-12. A mean skin temperature of $36^{\circ} \mathrm{C}$. was obtained when incubator air temperature was $35^{\circ} \mathrm{C}$. and no radiant shield was in place. The same skin temperature was obtained at an air temperature of $33.1^{\circ} \mathrm{C}$. when the shield was in place and mean radiant and air temperatures were the same. 